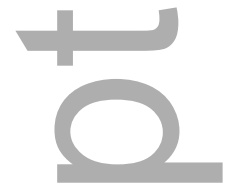

Article type : Full length original research paper

\title{
Twin Pregnancy in Women with Epilepsy
}

Frank J E Vajda ${ }^{\mathrm{ab}}$, Terence J O’Brien ${ }^{\mathrm{b}}$, Janet E Graham ${ }^{\mathrm{a}}$, Alison A Hitchcock ${ }^{\mathrm{a}}$,

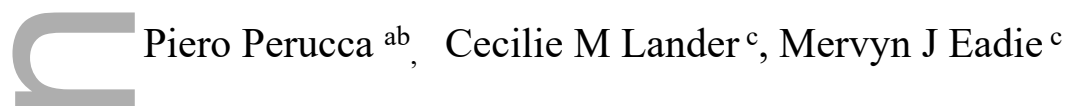

a Department of Medicine and Neurosciences, Royal Melbourne Hospital and University of Melbourne, Parkville, Victoria, Australia 3050

b Department of Neurology, Alfred Hospital \& Department of Neuroscience, Monash University, Commercial Road, Melbourne 3004, Australia

c Royal Brisbane and Women's Hospital and School of Medicine and Biomedical Science, University of Queensland, Brisbane, Queensland, Australia 4027

\section{Corresponding Author:}

Professor Frank J.E. Vajda

Address: Department of Medicine and Neurosciences, Royal Melbourne Hospital and University of Melbourne, Parkville, Australia 3050

Telephone: 61(3).98193056

E-mail: vajda@netspace.net.au

This is the author manuscript accepted for publication and has undergone full peer review but has not been through the copyediting, typesetting, pagination and proofreading process, which may lead to differences between this version and the Version of Record. Please cite this article as doi: 10.1111/EPI.16727

This article is protected by copyright. All rights reserved 
Number of text pages: 6 (excluding abstract, references, tables)

\section{Abstract word count: 248}

Manuscript word count: 1,561

Number of Tables: 3
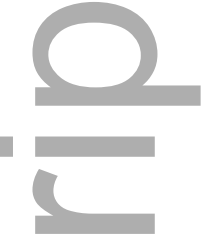

\section{Abstract}

Objective: We report data from the Raoul Wallenberg Australian Register of Antiepileptic Drugs in Pregnancy (APR) to see if there are significant differences in relation to the courses and outcomes of the twin pregnancies contained in the register, as compared with the singleton ones.

Methods: the APR has been under the oversight of Melbourne institutional Human Ethics Research Committees, All women enrolled in the APR have provide written informed consent. Data from the APR were transferred to a spreadsheet and then analysed using simple statistical techniques including logistic regression.

Results: The population studied comprised 44 twin and 2261 singleton pregnancies; thus, twin pregnancies accounted for $1.91 \%$ of all pregnancies studied. The women carrying twins tended to be older than the women with singleton pregnancies to a statistically significant extent, their pregnancies more often originated from assisted fertilization techniques, and their babies were more often delivered by Caesarean section. There were no statistically significant differences in relation to AED therapy, Individual twins had statistically significantly lower mean birthweights than singleton babies and they were statistically significantly more often involved structurally malformed foetuses. In the first year of life the twin pregnancies statistically significantly more often produced offspring that were affected by seizures in infancy

Significance: The data suggests that there may be an increased hazard of foetal malformation in offspring of twin pregnancy in women with epilepsy, but that with contemporary standards of management of epilepsy and pregnancy, there is unlikely to be an increased hazard of seizure-affected pregnancy. 


\section{Key Points: \\ Epilepsy and pregnancy}

Twin pregnancies in women with epilepsy

Small babies, more foetal seizures

Maternal seizures less likely

\section{Introduction}

In the past 20 years there has been a tremendous interest in the pregnancies of women with epilepsy, much of it concerned with the role of antiepileptic drugs (AEDs) in causing foetal malformations and in interfering with neurodevelopment in utero and afterwards. A considerable amount has been published regarding these matters, but little attention has been given to the matter of the outcome of twin pregnancies exposed to AED therapy in utero.

We have therefore analysed the data of the Raoul Wallenberg Australian Register of Antiepileptic Drugs in Pregnancy (APR) to see if there are significant differences in relation to the courses and outcomes of the twin pregnancies contained in the register, as compared with the singleton ones.

\section{Materials and methods}

Between 1999 (year of inception of the APR) and May 2020, the APR has recorded details of the pregnancies of a group of largely self-selected Australian women. These women had epilepsy or other disorders treated with AEDs, or had epilepsy that was untreated, at least at the outset of pregnancy. If such women became aware of the APR's existence through various means, and were planning pregnancy, or were already pregnant, they decided whether to participate. Additional details of the Register and of its policies and practices concerning data collection have been published elsewhere ${ }^{1,2}$. The APR has been estimated to contain information on about $8.7 \%$ of the relevant pregnancies that had occurred in Australia ${ }^{3}$. The present paper is concerned only with the APR pregnancies of women who had epilepsy. All contact between pregnant women and the APR has been via telephone. Data concerning each woman's medical details and pre-pregnancy epilepsy situation and the course of her pregnancy 
have been recorded (i) at enrolment, (ii) at approximately 28 weeks of pregnancy, (iii) within the first post-partum month, as far as possible, and (iv) at one year after giving birth (if the women remain contactable). The accuracy of the information provided by the pregnant women has been confirmed with their treating medical practitioners, whenever possible. The clinical management of the women involved has always remained the responsibility of the treating medical practitioners and the APR's personnel have not attempted to influence it. Over the years, the APR has been under the oversight of various Melbourne based institutional Human Ethics Research Committees, currently that of Melbourne Health. All women enrolled in the APR have provide written informed consent before participation.

For the purposes of the present study, data from the APR were transferred to a spreadsheet and then analysed using simple statistical techniques including and logistic regression.

\section{Results}

The population studied comprised 44 twin and 2261 singleton pregnancies; thus, twin pregnancies accounted for $1.91 \%$ of all pregnancies studied. Details of the potentially relevant characteristics of the women and pregnancies are provided in Table 1. The women carrying twins tended to be older than the women with singleton pregnancies to a statistically significant extent, their pregnancies more often originated from assisted fertilization techniques, and their babies were more often delivered by Caesarean section. There were no statistically significant differences between the women involved in the twin and singleton pregnancies in relation to AED therapy, and in the rates of overall use of the individual more commonly prescribed AEDs as listed in Table 1.

Foetal outcomes: The individual twins not unexpectedly had statistically significantly lower mean birthweights than the singleton babies. The twin pregnancies statistically significantly more often involved structurally malformed foetuses (Table 2), and in the first year of postnatal life the twin pregnancies statistically significantly more often produced offspring that were affected by seizures in infancy. In pregnancies that followed assisted fertilisation, malformed foetuses occurred more often in 14 twin than in 2250 singleton ones $(14.3 \%$ versus $10.1 \%$; O.R. $=1.485,95 \%$ C.I. $1.357,1.632)$. In the same pregnancies, seizures in infancy also were more common in the offspring of the twin-bearing ones $(15.4 \%$ versus $3.9 \%$; $95 \%$ C.I. $4.076,4.989)$. In pregnancies unrelated to assisted fertilisation, the foetal malformation rate 
remained higher in 30 twin than in 2111 singleton pregnancies $(16.7 \%$ versus $6.2 \%$ : O.R. $=$ 3.048; 95\% C.I. 2.881, 3.224).

Because different AED therapy in pregnancies might have contributed to the increased foetal malformation rates in the twin pregnancies, multiple variable logistic regression was used to analyse the possible role of such therapy (Table 3), with progressive deletion of covariates with $\mathrm{P}$ values making them unlikely to be significant. Throughout the process, twin pregnancy as a factor contributing to an increased foetal malformation rate continued to show $\mathrm{P}$ values $<0.04$, though dosages of valproate, carbamazepine and topiramate had even more significant $\mathrm{P}$ values.

All three pregnancies in which offspring had seizures in infancy had occurred in women with genetic generalized epilepsies, and this type of epilepsy was also present in $66 \%$ of the 44 singleton pregnancies where infants had seizures in their first year of post-natal life. (This percentage may be unexpected as the prevalence of focal epilepsies in populations is higher than that of genetic generalized epilepsy).

Maternal seizures: The women involved in the twin pregnancies tended to have higher incidences of seizure-affected years before pregnancy, lower incidences of seizure-affected pregnancies, and higher incidences of seizure-affected periods after pregnancy, but none of these differences was statistically significant. Fewer of the twin pregnancies with seizure affected pre-pregnancy years went on to have seizures during pregnancy $(61.9 \%$ of 21 pregnancies) as compared with the singleton pregnancies (78.5\% of 958), a difference not quite statistically significant (O.R. $=0.445,95 \%$ C.I. $0.182,1.089)$.

However, logistic regression analysis (Table 3) showed that, independent of the effects of other co-variates considered, twin pregnancy did have a statistically significant effect in reducing the occurrence of seizure affected pregnancy. This finding raised the possibility that a higher incidence of pregnancy referral to the APR by neurologists might have resulted in more skillful management of epilepsy in pregnancy other than in handling drug therapy. However, $45.5 \%$ of the twin pregnancies, but $48.1 \%$ of the singleton ones, had been referred by neurologists.

\section{Discussion}

We have not been able to find in the recent literature any publication devoted specifically to the topic of twin pregnancy in women with epilepsy. There are a few papers in which the 
presence of small numbers of twin pregnancies in such women has been mentioned, but the matter not taken further. In one paper based on the EURAP register ${ }^{4}$, there were 51 twin pregnancies among a total of 3909 pregnancies, though an uncertain number of these pregnancies will also be included in the APR data. Another ${ }^{5}$ described the occurrence of 21 twin pregnancies in a total of 1687 pregnancies, though again it is likely to some of these pregnancies were included in the EURAP 2011 data.

The twin pregnancy rate in the present study $(1.91 \%)$ was higher than the general $1.4 \%$ rate that has applied in Australia over the past decade ${ }^{6}$, but this may simply reflect the population studied in this paper being a self-selected one.

Several of the statistically significant differences between the twin and singleton pregnancies in the present investigation, e.g. the lower birth weights of the offspring of the twin pregnancies, the higher incidence of pregnancy following assisted fertilization, and the greater use of Caesarean section are clearly related to obstetrical factors. The major findings of significance that have emerged from the study were the higher incidence of malformationsbearing pregnancies and the probable lesser tendency to have seizure-affected pregnancy in the twin pregnancies group. The higher incidence of congenital malformations in the twin pregnancy group might be partly attributable to a higher proportion of twin pregnancies being exposed to valproate than singleton pregnancies (31.8\% versus $22.1 \%)$, although this difference did not reach statistical significance (Table 1). Obstetric factors known to increase the risk of adverse reproductive outcomes in the general population, e.g. older maternal age, a history of infertility, twin pregnancy per se, lower birthweight, and use of assisted reproductive technology, ${ }^{7-9}$ might have also played a role in the differences in rates of foetal malformations as well as seizures in infancy between the pregnancy groups. However, in our regression analyses, maternal age and birthweight were not found to be significant confounders in the relationship between foetal malformations and twin pregnancy (Table 3). The higher foetal malformation rate in the twin pregnancies also persisted after pregnancies initiated by assisted fertilisation were deleted from consideration. The rate of occurrence of malformation-carrying pregnancy in the twin group (15.9\%) is not grossly dissimilar to the $11.8 \%$ rate recorded by Tomson et al ${ }^{4}$ but comparisons are made uncertain by the probable inclusion of some Australian twin pregnancies in the database used in the paper based on the EURAP register. ${ }^{4}$

The present paper is based on a not particularly large collection of twin pregnancies in Australian women with epilepsy who to a degree selected themselves for study and who may 
not necessarily be representative of the wider national community of women with epilepsy, let alone the international one. Further, potentially includable pregnancies that abort before enrolment are lost to the study. Bearing these circumstances in mind, the present experience suggests that there may well be an increased hazard of foetal malformation in the offspring of twin pregnancy in women with epilepsy, independent of any effect of AED therapy but that with contemporary standards of management of epilepsy and pregnancy, there is unlikely to be an increased hazard of seizure-affected pregnancy.

\section{References}

1. Vajda FJ, Hitchcock A, Graham J, O'Brien T, Lander C, Eadie M. The Australian Register of Antiepileptic Drugs in Pregnancy: the first 1002 pregnancies. Aust N Z J Obstet Gynaecol. 2007; 47(6):468-474.

2. Vajda FJ. The Australian Pregnancy Register of Anti-epileptic Drugs: 10 years of progress. J Clin Neurosci. 2010; 17(12):1485-1488.

3. Vajda FJ, O'Brien TJ, Graham J, Lander CM, Eadie MJ. The Australian Register of antiepileptic drugs in pregnancy: changes over time in the epileptic population. J Clin Neurosci. 2014; 21(9):1478-1482.

4. Tomson T, Battino D, Bonizzoni E, et al. Dose-dependent risk of malformations with antiepileptic drugs: an analysis of data from the EURAP epilepsy and pregnancy registry. Lancet Neurol. 2011; 10 (7):609-617.

5. Thomas SV, Jose M, Divakaran S, Sankara Sarma P. Malformation risk of antiepileptic drug exposure during pregnancy in women with epilepsy: Results from a pregnancy registry in South India. Epilepsia. 2017; 58 (2):274-281. 
6. Australian Bureau of Statistics, 3301.0 - Births Australia 2018. Link: https:/www.abs.gov.au/Ausstats/abs@.nsf/7d12b0f6763c78caca257061001cc588/d15741a33 fe7373cca257aa100128adf!OpenDocument. Accessed on 14 September 2020.

7. Layde PM, Erickson JD, Falek A, McCarthy BJ. Congenital malformation in twins. Am J Hum Genet. 1980; 32 (1):69-78.

8. Sherer DM. Adverse perinatal outcome of twin pregnancies according to chorionicity: review of the literature. Am J Perinatol. 2001; 18(1):23-37

9. Glinianaia SV, Rankin J, Wright C. Congenital anomalies in twins: a register-based study. Hum Reprod. 2008; 23 (6):1306-1311.

\section{Acknowledgements}

We acknowledge the help provided by professional and lay colleagues who referred patients to the Australian Pregnancy Register, and wish to thank the Scientific Advisory Board and the Ethical Research Committees of St. Vincent's Hospital, Monash Medical Centre, the Royal Melbourne Hospital and other institutions for their continuing ethics oversight of the Register. The Register is grateful for support from the Epilepsy Action Australia (principal sponsor), Epilepsy Society of Australia, The Royal Melbourne Hospital Neuroscience Foundation, and financial assistance from the NHMRC and the pharmaceutical companies Sanofi-Aventis, Genzyme, UCB Pharma, Janssen-Cilag, Sci-Gen, and Eisai.

\section{Conflicts of Interest}

F J E Vajda has received research support for the Australian Pregnancy Register from the Epilepsy Society of Australia, NHMRC, RMH Neuroscience Foundation, Epilepsy Action, Sanofi-Aventis, UCB Pharma, Janssen-Cilag, Novartis, and Sci-Gen.

T O'Brien has received research support from the Epilepsy Society of Australia, NHMRC, RMH Neuroscience Foundation, Sanofi-Aventis, UCB Pharma, Janssen-Cilag, Novartis, and Sci-Gen.

P Perucca is supported by the National Health and Medical Research Council (APP1163708), the Epilepsy Foundation, the Royal Australasian College of Physicians, Monash University, and Melbourne Health. He has received speaker honoraria or consultancy fees to his institution from Eisai, UCB Pharma, Sun Pharma, Novartis, and Supernus. 
J E Graham, AA Hitchcock, C M Lander and M J Eadie have no relevant conflicts of interest to declare.

\section{Ethical Publication Statement}

We confirm that we have read the Journal's position on issues involved in ethical publication and affirm that this report is consistent with these guidelines.

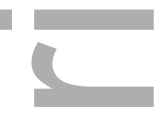

Table 1. Comparison of twin and singleton pregnancies.

\begin{tabular}{|c|c|c|c|c|}
\hline & $\begin{array}{c}\text { Twin } \\
(\mathrm{N}=44)\end{array}$ & $\begin{array}{l}\text { Singleton } \\
(\mathrm{N}=2261)\end{array}$ & $\begin{array}{c}\text { Difference } \\
\text { or O.R. }\end{array}$ & 95\% C.I. \\
\hline \multicolumn{5}{|l|}{ Maternal characteristics } \\
\hline Mother's age (years) & $32.5 \pm 3.6$ & $31.0 \pm 4.6$ & 1.5 years $^{\mathrm{d}}$ & $0.14,2.92$ years* \\
\hline With generalised epilepsy & $20(45.5 \%)$ & $979(43.3 \%)$ & 1.091 & $0.599,1.987$ \\
\hline With focal epilepsy & $22(50.0 \%)$ & $1092(48.3 \%)$ & 1.071 & $0.590,1.944$ \\
\hline Epilepsy onset age (years) & $18.8 \pm 8.2$ & $17.0 \pm 8.2$ & 1.8 years $^{\mathrm{d}}$ & $-0.7,4.2$ years \\
\hline Primiparous & $14(31.8 \%)$ & $939(41.5 \%)$ & 0.657 & $0.347,1.246$ \\
\hline Neurologist referral & $20(45.5 \%)$ & $1087(48.1 \%)$ & 0.900 & $0.494,1.639$ \\
\hline Enrolled before 20 weeks & $25(56.8 \%)$ & $1050(46.4 \%)$ & 1.518 & $0.831,2.771$ \\
\hline Assisted fertilisation & $14(31.8 \%)$ & $139(6.2 \%)$ & 7.124 & $3.693,13.745^{*}$ \\
\hline - by IVF & $11(25.0 \%)$ & $71(3.1 \%)$ & 10.282 & $4.994,21.168^{*}$ \\
\hline Delivery - Caesarean & $36(81.8 \%)$ & $846(37.4 \%)$ & 7.527 & $3.482,16.269^{*}$ \\
\hline \multicolumn{5}{|l|}{ Infant characteristics } \\
\hline Livebirth with no foetal malformations & $36^{\mathrm{a}}(81.8 \%)$ & $2066(91.4 \%)$ & 0.485 & $0.213,1.105$ \\
\hline Spontaneous abortion & $1(2.3 \%)$ & $58(2.6 \%)$ & 0.883 & $0.120,6.525$ \\
\hline Still born & 0 & 17 & & \\
\hline Birth weight (grams) & $2428 \pm 716$ & $3888 \pm 558$ & $1460 \mathrm{gm}^{\mathrm{d}}$ & $1287,1634 \mathrm{gm}^{*}$ \\
\hline Foetal malformation & $7^{\mathrm{b}}(15.9 \%)$ & $146(4.5 \%)$ & 2.740 & $1.201,6.254^{*}$ \\
\hline Seizures in infancy & $3^{\mathrm{c}}(6.8 \%)$ & $45(2.0 \%)$ & 3.603 & $1.076,12.069^{*}$ \\
\hline \multicolumn{5}{|l|}{ Maternal epilepsy behaviour } \\
\hline Seizures - Pre-pregnancy year & $21(47.7 \%)$ & $958(42.2 \%)$ & 1.242 & $0.683,2.257$ \\
\hline In pregnancy & $15(34.1 \%)$ & $1029(45.5 \%)$ & 0.619 & $0.330,1.161$ \\
\hline - In labour & 0 & $48(2.1 \%)$ & & \\
\hline - $\quad$ After pregnancy & $10(22.7 \%)$ & $433(18.7 \%)$ & 1.278 & $0.616,2.607$ \\
\hline \multicolumn{5}{|l|}{ Maternal AED Therapy } \\
\hline No AEDs & $1(2.3 \%)$ & $185(8.2 \%)$ & 0.261 & $0.036,1.906$ \\
\hline AED Monotherapy & $34(77.3 \%)$ & $1675(74.1 \%)$ & 1.190 & $0.584,2.243$ \\
\hline
\end{tabular}




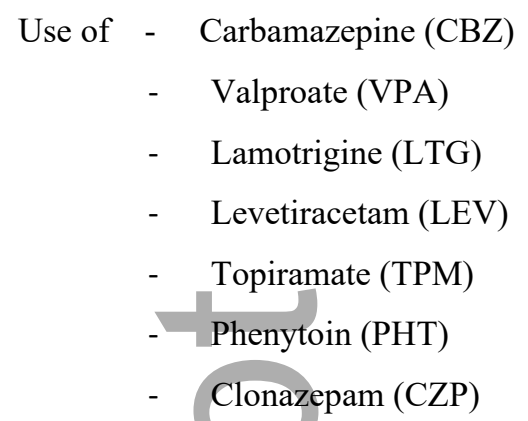

$\begin{array}{cc}8(18.2 \%) & 624(27.6 \%) \\ 14(31.8 \%) & 500(22.1 \%) \\ 14(31.8 \%) & 732(32.4 \%) \\ 8(18.2) & 370(16.4) \\ 5(11.4 \%) & 161(7.1 \%) \\ 2(4.6 \%) & 83(3.7 \%) \\ 4(9.1 \%) & 109(4.8 \%)\end{array}$

0.583

$0.270,1.261$

$0.865,3.124$

$0.514,1.850$

$0.524,2.463$

$0.650,4.301$

$0.297,5.250$

$0.694,5.618$

${ }^{*} \mathrm{P}<0.05 ;{ }^{a}$ in all of these 36 twin pairs, both live-born twins had no foetal malformations. There 4 additional twin pairs, in which one of the twins was a livebirth without malformations. Hence, there was a total of 76 non-malformed livebirths. ${ }^{b}$ In 4 of the 7 twin pairs with foetal malformations, only one of the twins had one or more malformations. In the other 3 twin pairs, both twins had one or more malformations. Hence, there was a total of 10 malformed foetuses from the 7 twin pregnancies (Table 2). ${ }^{\mathrm{c}}$ In each of these 3 twin pairs, seizures occurred in only one of the twins. ${ }^{\mathrm{d}}$ difference.

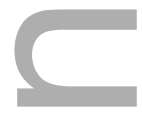

Table 2. Malformations in the twin pregnancy offspring.

\begin{tabular}{|c|c|c|c|c|}
\hline Mother & $\begin{array}{c}\text { Assisted } \\
\text { fertilisation }\end{array}$ & $\begin{array}{c}\text { AED } \\
\text { (mg/day) }\end{array}$ & M or $F$ & Malformation(s) \\
\hline \multirow[t]{2}{*}{ A } & & VPA (2000) & $?$ & Spina bifida, hydrocephalus - aborted \\
\hline & & & $\mathrm{F}$ & Polydactyly, plagiocephaly, craniosynostosis \\
\hline \multirow[t]{2}{*}{ B } & - & VPA (1500) & M & Hypospadias \\
\hline & & & M & Nil \\
\hline \multirow[t]{2}{*}{$\mathrm{C}$} & & LTG (500) & $?$ & Hypoplastic left heart - aborted \\
\hline & & & $?$ & Hypoplastic left heart - aborted \\
\hline \multirow[t]{2}{*}{$\mathrm{D}$} & & VPA (1000) & $\mathrm{F}$ & Fallot tetralogy \\
\hline & & & $\mathrm{F}$ & Nil \\
\hline \multirow[t]{2}{*}{$\mathrm{E}$} & & VPA (1000) & $\mathrm{F}$ & Ventricular and atrial septal defects \\
\hline & & & $\mathrm{F}$ & Nil \\
\hline \multirow[t]{2}{*}{$\mathrm{F}$} & Hormonal & LEV (2000) & M & Late recognised blepharophimosis \\
\hline & & $+\mathrm{CZP}(0.5)$ & M & Nil \\
\hline \multirow[t]{2}{*}{ G } & IVF & CBZ (800) & M & Ventricular septal defect, hypospadias \\
\hline & & & M & Ventricular septal defect \\
\hline
\end{tabular}


Table 3. Constants and co-variate values and the corresponding $P$ values after sequential stripping of unlikely co-variates from logistic regressions for occurrence of malformed foetus and seizure-affected pregnancy rates on potentially relevant data factors. Co-variates stripped from the equations included maternal age, low birth weight, age at seizure disorder onset, and, in relation to seizure-affected pregnancy, assisted fertilisation.

\begin{tabular}{|c|c|c|c|c|}
\hline & \multicolumn{2}{|c|}{ Malformed foetus } & \multicolumn{2}{|c|}{ Seizure-affected pregnancy } \\
\hline & & $P$ & & $P$ \\
\hline Constant & -3.16791 & $<0.0001$ & -1.60841 & $<0.0001$ \\
\hline Co-variates & & & & \\
\hline Twins & +0.90838 & 0.0386 & -0.91665 & 0.0167 \\
\hline Assisted fertilisation & +0.72453 & 0.0176 & & \\
\hline Pre-pregnancy seizures & & & +2.46902 & $<0.0001$ \\
\hline Generalised epilepsy & & & -0.27906 & 0.0123 \\
\hline No AED use & & & +0.81804 & $<0.0001$ \\
\hline CBZ dose & +0.00061 & 0.0065 & +0.00022 & 0.0103 \\
\hline CZP dose & & & +0.13135 & 0.1119 \\
\hline LEV dos & & & +0.00017 & 0.0244 \\
\hline LTG dose & & & +0.00173 & $<0.0001$ \\
\hline PHT dose & & & +0.13235 & 0.0340 \\
\hline TPM dose & +0.00258 & 0.0063 & +0.00323 & 0.0003 \\
\hline VPA dose & +0.00106 & $<0.0001$ & +0.00022 & 0.0832 \\
\hline
\end{tabular}




\section{University Library}

\section{- M M N E R VA A gateway to Melbourne's research publications}

Minerva Access is the Institutional Repository of The University of Melbourne

Author/s:

Vajda, FJE;O'Brien, TJ;Graham, JE;Hitchcock, AA;Perucca, P;Lander, CM;Eadie, MJ

Title:

Twin pregnancy in women with epilepsy

Date:

2020-12

Citation:

Vajda, F. J. E., O'Brien, T. J., Graham, J. E., Hitchcock, A. A., Perucca, P., Lander, C. M. \& Eadie, M. J. (2020). Twin pregnancy in women with epilepsy. EPILEPSIA, 61 (12), pp.2748-2753. https://doi.org/10.1111/epi.16727.

Persistent Link:

http://hdl.handle.net/11343/276568 